\title{
Methods of teaching medical ethics at the University of Nottingham
}

\author{
P H Fentem Department of Physiology and Pharmacology, Medical School, University of Nottingham
}

\section{Author's abstract}

Medical ethics has been described as a thread woven into the fabric of the Nottingham curriculum. There exist a wide variety of relevant learning experiences, occurring at intervals throughout each of the five years of the course. The introduction of the students to clinical method from the start creates the need for early consideration of ethical aspects of professional behaviour and this in turn stimulates spontaneous discussion and inquiry amongst the students. The school has chosen to rely on having a sufficient number of medical teachers from various disciplines willing to discuss in all the necessary detail their own clinical decisions.

This account of the ways in which Nottingham medical students learn about medical ethics is based upon a series of conversations between the author, when he was Vice Dean, and individuals who were either current undergraduate medical students, qualified doctors graduating from Nottingham, or teaching staff with responsibility for relevant parts of the curriculum. An attempt was made to assemble a commentary based upon consideration of both the formal and informal learning which occurs.

Jones and Metcalfe (1) described the plan of the Nottingham medical curriculum in which they saw medical ethics as a thread woven into the fabric of the course. This is still a valid description of the place of medical ethics in the Nottingham curriculum. Of the two possible strategies discussed by Jewell (2), reliance is placed upon having sufficient numbers of medical teachers from various disciplines who have the necessary skills and are willing to discuss their own clinical decisions. The alternative, of appointing ethical experts to the teaching staff with the intention that it should be they who discuss with students the decisions made by clinicians has been eschewed.

The medical school has declared objectives which include reference to the need for doctors to be imbued with high ethical standards and to have developed, during their training, attitudes to the practice of

\section{Key words}

Undergraduate medical curriculum; student initiatives in learning.

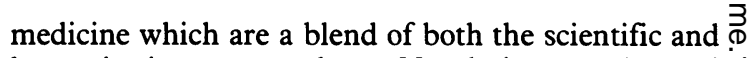
humanitarian approaches. Moral issues, doctors' $\overrightarrow{ }$ attitudes, professional standards and legal obligations $\overrightarrow{-}$ are discussed with the students at various stages during the five years of the course. There is no deliberate 0 attempt to disentangle these issues until the final year when the students receive a short course of six lectures.

\section{The basic medical science course}

During the second week of their first term all students $\vec{\oplus}$ are given an opportunity to view the whole range of or medical care by visits to general practitioners' surgeries, health centres and hospital wards. These introductory visits are arranged under the general title of The Scope and Responsibilities of Medicine. They are designed to demonstrate the range of health services, but particularly the roles of different doctors and the responsibilities which they have to face and to fulfil. This is perhaps the students' first exposure to the idea that few questions in medicine can be answered without an associated degree of uncertainty.

At about the same time the students receive a formal lecture on medical ethics which is essentially an explanation of ethics and a discussion about their place in medicine. In this lecture a further attempt is made to explain the scale of the problems posed for the doctor by the varying degrees of uncertainty which surround clinical decision-making. The lecturer explains to the students why they should attempt to know and understand the doctors whose work they are observing and why they can expect a wide diversity of $\mathscr{O}$ professional behaviour. The students appear to need $N$ this help in recognising the attitudes of the doctors from whom they are learning and to have their attention drawn to sources of help, should they subsequently decide that they want to discuss any aspect of these.

These early opportunities for discussion and explanation are important because clinical method is taught from the start of the course. Even in their first term Nottingham students can expect to listen to a patient describing his or her illness in private and alone. The course in the behavioural sciences is designed to provide a sound and supportive 8 preparation for these - the students' first clinical interviews. Throughout the basic medical course, as 
the students learn about each system, they will take a history from and examine a patient, conducting these with reference to the system under consideration. Thus the student rapidly acquires an experience of the wider issues of medicine sufficient to provide the content for informal debate and discussion. Student comment highlights the importance of providing this content.

The course entitled 'Medicine and the Medical Student' takes place in the first term. This course of four lectures, given by general practitioners of the staff of the school, has ostensibly nothing to do with ethics. The lectures are concerned with problems of drug abuse, alcohol abuse, venereal disease and contraception, and are intended to support the students, recognising that as a group they acquire a unique professional identity among the student community. These lectures are said to arouse more debate amongst the students on ethical issues than most other classes, even those which are organised to be more explicitly concerned with medical ethics.

Within the basic medical sciences course, the laboratory teaching of physiology and pharmacology is based on experiments performed on man, providing opportunities tor students to be both the subject and the experimenter. This is a good context in which to consider 'the volunteer' and 'consent' and to introduce the idea of responsibility. The course in community health provides an opportunity for the consideration of other ethical issues. This course is concerned with the delivery of health care and introduces the students to the difficult 'choices' which face doctors with increasing frequency, for example selection for renal dialysis and the problems of choice when planning health care for the Third World.

During the third year, when all the students study a single medical science for the Part II of the degree of Bachelor of Medical Science, individual students confront the ethics of medicine more directly. Project work may involve research, albeit closely supervised, in the community or the ward. The students are thus brought into direct contact with the problems of preparing ethical submissions and of having their protocols scrutinised by an ethical committee. They are encouraged to discuss fully all the issues raised by their work.

During the clinical course there are topics which are identified specifically for ethical consideration and these form the subjects for large group seminars during the teaching of Psychiatry, Child Health, Obstetrics and Gynaecology and Health Care of the Elderly. There is a general insistence that total patient care cannot be discussed adequately without raising the related ethical issues. Each department identifies key areas for special consideration: for example, during the paediatric attachment the students attend the courts and case conferences concerning disadvantaged children, children who must be removed from their parents, and those who have severe mental handicap.

If the students have any criticism at all of the way in which the school handles the teaching of medical ethics, it is that some feel an unfulfilled need for reassurance and support during their first clinical contacts as junior clerks. The students considered their understanding of medical ethics was developed the most effectively during the four weeks' attachment to a general practitioner.

The final group of lectures which are held during the last clinical year concern the medico-legal and professional aspects of ethics. The topics covered include consent, confidentiality, 'ownership' of records, the Human Tissues Act, and the GMC.

The 'alternative' curriculum depends upon student initiatives and spontaneous discussion. Elsewhere it has led to the formation of 'Medical Groups'. It is much more important in this field of medical education than any other. The students were quite sure of the relevance of the curricular lectures on 'Medicine and the Medical Student' but extracurricular discussions between experts have been notably unsuccessful.

At Nottingham the Christian Fellowship, the Interfaculty Christian Union and the Questioning Medicine Group have fully served the needs of some students for extracurricular discussion.

The students from whom views were sought considered that medical ethics did receive due attention and appreciated the wide variety of relevant learning experiences which had been included in the curriculum. They recognised, as do the academic staff, that there will always be some of their number who remain insensitive to ethical issues. Even these students however are more likely to be influenced by the predominant attitude of the faculty than by a department of experts. The author of this paper is left unconvinced that any special and further advantage will accrue from doing more to pull together the relevant learning experiences under the umbrella of yet another discipline, namely medical ethics.

\section{References}

(1) Jones J S P, Metcalfe D H H. The teaching of medical ethics in the Nottingham Medical School. Fournal of medical ethics 1976; 2: 83-86.

(2) Jewell M D. Teaching medical ethics. British medical journal 1984; 289: 364-365. 